\title{
Electric Field Distribution In Transformer Bushing
}

\author{
Zubair $\mathrm{Ali}^{1}$, Mohsin Ali Tunio ${ }^{2}$, Nadeem Ahmed Tunio ${ }^{2}$, Shazia Feroz ${ }^{3}$
}

\begin{abstract}
The bushings are insulating devices of the power system they allow electrical conductors to pass current and resist the flow of current to the conducting tanks in case of transformers and circuit breakers. These bushings are typically made of porcelain material. The bushing must be designed to withstand electrical as well as mechanical stresses. The electric field stresses may develops the leakage paths within the insulation and if these stresses increased beyond the dielectric strength of insulation, it may puncture the bushing insulation and will allow the electric current to pass through earthed material causing burning and arcing. Mostly the electric field is not uniformly across the bushing therefore, a simulation is carried out to analyze and calculate the characteristics of electric field distribution In this paper, a transformer porcelain solid type bushing with oil as cooling and dielectric material is used. The Finite Element Analysis (FEM) technique is used to calculate electric field distribution along the solid type bushing transformer. It is projected that the results will provide an improved understanding of the EF distribution on the bushing outlet. This study may also assist in scheming HV bushing which can reduce the magnitude EF in the bushing.
\end{abstract}

Keywords: Bushing, Electric Field (EF) distribution, Finite Element Analysis (FEA).

\section{Introduction}

HV bushing insulators are used to provide weather proof protection for the exposed ends of transformer. A bushing consists of a hollow insulating line from which HV conductor passes through an earthed wall, such as the metal tank that encloses an oil insulated transformer. The bushing insulates the HV conductor from earth and also provides a means of mechanically supporting the conductor. The bushings connect the transformer windings, supply line and insulate the feeder via conductor from the main tank of the transformer. According to the electrical and physical observation, bushing is the feeblest part of the transformer. Besides HV bushing is the connection between outer and inner insulating schemes. The HV is fed into the transformer vessel and has to endure high loads, the electric field strength, mechanical forces, chemical loads and contaminations because of environmental and thermal pollution. For this reason, the bushings plays significant role in the operation of $\mathrm{HV}$ equipment [1].

\footnotetext{
${ }^{1}$ Master of Engineering Student, Department of Electrical Power Engineering, Mehran University of Engineering and Technology Shaheed Zulfiqar Ali Bhutto Campus Khairpur Mir's

Lecturer, Vocational Training Centre Khairpur, Sukkur IBA University

Corresponding Email: zubairaliphulpoto@yahoo.com

${ }^{2}$ Department of Electrical Engineering, Mehran University of Engineering and Technology Shaheed Zulfiqar Ali Bhutto Campus Khairpur Mir's

${ }^{3}$ Assistant Professor, Benazir Bhutto Shaheed University of Engineering Technology \& Skill Development Khairpur Mir's. 
The reliability of bushing is crucial for the operation of the transformer. Bushings mechanically support external conductors and provide insulation from earth as the conductors are fed into the transformer tank. Moreover, bushings are one of the important elements of transformers and it was found to be the most common reasons of disastrous breakdown of transformers and nearby protective devices [2].

The transformers are one of the most intentional and expensive equipment of electrical power system. It was found from past literature that almost 25 to $30 \%$ of transformer breakdown are due to the bushing failure [3-5]. Since transformer bushings have no moving parts, most failures are attributed to insulation deterioration from moisture ingress [6] and electrical discharges. The bushing represents only a small fraction of the power transformer cost but their failure is often catastrophic. Failures do not only damage the transformer but can often cause significant damage to equipment in the proximity and consequently causes significant disruption. The study of the EF distribution along outer surface of the bushing is of key importance as it is used to evaluate the potential initiation of partial discharges. The reliability of bushing is crucial for the operation of the transformer. Bushings mechanically support external conductors and provide insulation from earth as the conductors are fed into the transformer tank [4].

The majority of bushings in the real practice are as old as the transformers. So monitoring the bushing condition and its maintenance is necessary. All HV bushings should be examined frequently every 3-5 years. During inspection if deterioration sign is found then bushing should be examined every 6 months and detached from service if the tests display a hazardous condition [2]. The commencement of bushing failure is not easily detectable at the initial stage that could later lead to an unwanted failure of the bushing, even though breakdown of the transformer. Insulation breakdown is one of the severe failures of transformers which can produce extensive financial losses of the utility. Consequently, utilities are recommended to continually check the conditions of transformers to avoid unwanted power outage and decrease failure rate. However, the formation of voids and air bubbles during modeling, installation and operation of insulating equipments is the main cause of insulator flashover and deterioration of power equipments. The presence of voids and air bubbles inside the dielectric material has lesser value of permittivity than the surrounding insulating material and higher electric field stresses that could lead to formation of weak spots in the insulation.

In power transformer, the oil-paper insulation has been extensively incorporated in the designing of bushing structures due to its decent heat transfer and electrical properties. Though, lengthy experience to severe electrical, mechanical and thermal stresses can weaken the oil vital possessions and split the paper insulation bonds resulting in the production of water, carbon dioxide, carbon monoxide. Partial discharge (PD) activity can be generated if air bubbles are found in the insulation and can carbonize the material (insulation) forming conducting paths which can ultimately short out bushing layers. The lack of mechanical and thermal stresses could also be the cause of lack of continuity of the conducting bushings and arcing [2]. Therefore, transformer bushings have been designed in such a way that reduces field stresses at transformer insulation.

\section{Mathematical Formulation}

The distribution of EF is obtained using the electric potential (EP) equation. The basic principal field equations of the model are.

$$
\vec{\nabla} \bullet \vec{D}=\rho_{f}
$$




$$
\frac{\partial \rho_{f}}{\partial t}+\overrightarrow{J_{f}} \bullet \vec{\nabla}=0
$$

Where equation 1 and 2 shows the field model and current continuity equations respectively. $J_{f}, \rho_{f}$ and $\mathrm{D}$ are the free current density, charge density and the electric displacement field respectively.

\section{Model Description}

The '2D axial symmetry' model was built in COMSOL Multi-physics; the 'Quasistatic electric' is selected under the 'AC /DC module' to solve the EF distribution. Figure 1 shows a transformer bushing model and its dimensions and components. To model the distribution of EF along surface of the bushing (outer), the model is enclosed by air. The boundary conditions for transformer bushing model geometries are given in Table I and the associated material properties used to set the sub domains are given in Table II. Figure 2 and 3 shows the 2D axial-symmetric model geometry, the mesh elements and the boundaries for calculation of electric field distributions.

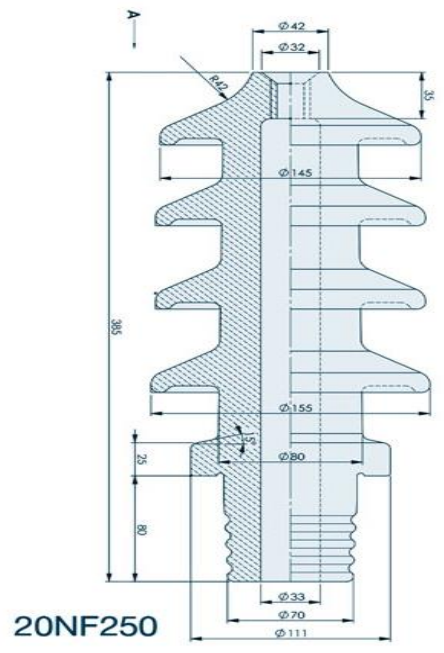

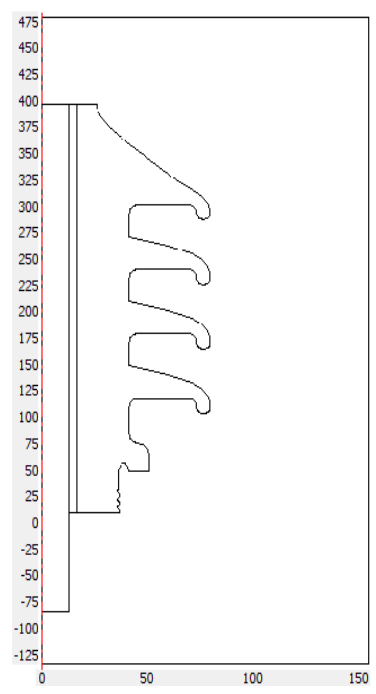

(a)

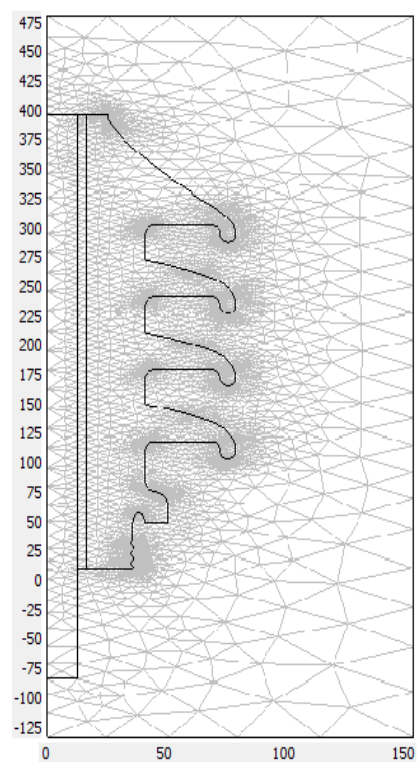

(b)

Fig. 2. 2D axial-symmetric transformer bushing (a) model geometry and (b) with meshing.

Fig. 1. 2D transformer bushing model [7]. 
TABLE I. Model boundary conditions

\begin{tabular}{|c|c|c|}
\hline $\begin{array}{c}\text { Boundary } \\
\text { line }\end{array}$ & $\begin{array}{c}\text { Boundary } \\
\text { condition }\end{array}$ & Description \\
\hline $\begin{array}{c}\text { Green and } \\
\text { black line }\end{array}$ & $\begin{array}{c}\text { Electric } \\
\text { Potential }\end{array}$ & $\begin{array}{c}\text { Conductor } \\
\text { boundaries }\end{array}$ \\
\hline $\begin{array}{c}\text { Red dotted } \\
\text { line }\end{array}$ & $\begin{array}{c}\text { Axial } \\
\text { Symmetry }\end{array}$ & $\begin{array}{c}\text { Boundaries } \\
\text { along } r=0 \\
\text { line }\end{array}$ \\
\hline Pink line & $\begin{array}{c}\text { Floating } \\
\text { Potential }\end{array}$ & $\begin{array}{c}\text { Outer surface } \\
\text { of the cap }\end{array}$ \\
\hline Blue line & Continuity & $\begin{array}{c}\text { Bushing } \\
\text { interior } \\
\text { boundaries }\end{array}$ \\
\hline
\end{tabular}

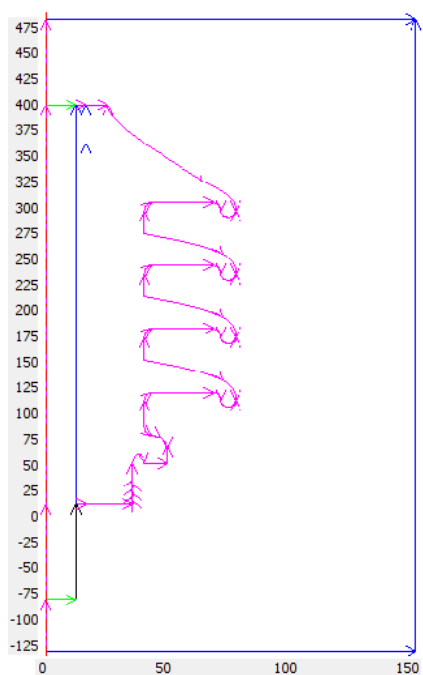

Fig.3. Bushing model geometry with boundaries.

TABLE II. Sub-domain settings in model geometry.

\begin{tabular}{|c|c|}
\hline Material & Permittivity $\boldsymbol{\varepsilon}_{\mathbf{r}}$ \\
\hline Air & 1 \\
\hline Porcelain cap & 6 \\
\hline Aluminium & 1 \\
\hline Oil & 2.3 \\
\hline
\end{tabular}

\section{Simulation Results}

The simulation of EF distribution in the developed model is shown in Figure 4. The entire structure length is $385 \mathrm{~mm}$, diameter of conductor and bushing (plate) is $12 \mathrm{~mm}$ and the $155 \mathrm{~mm}$ respectively. The applied voltage is $11 \mathrm{kV}$, the magnitude of maximum EF is observed at the cap of porcelain as this part of the cap has floating potential boundary. The maximum EF is found to be $805.887 \mathrm{~V} / \mathrm{m}$ at the porcelain cap (edge) region. The oil as the insulation material of the conductor reduces the $\mathrm{EF}$ magnitude around the conductor region.

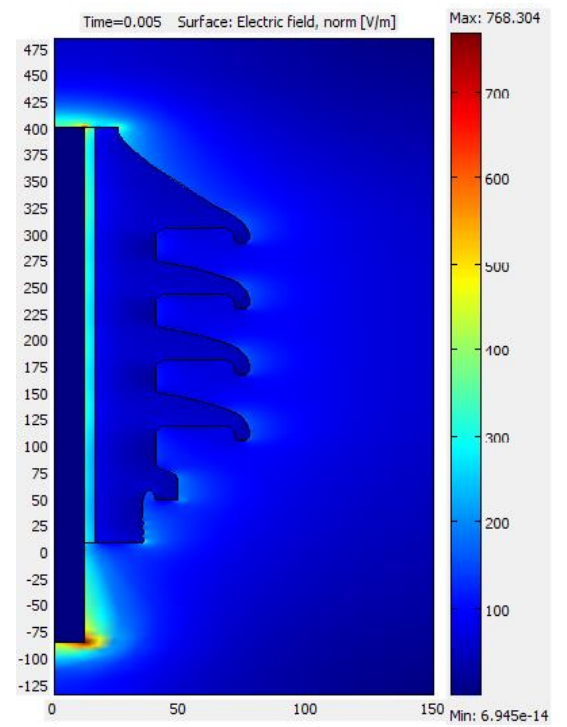

Fig. 4. Simulated electric field distribution in transformer bushing.

Figure 5 shows the plot of magnitude of the $\mathrm{EF}$ in the developed model. It has been found that the magnitude of the EF is not uniform and is because of materials having different permittivity value in the structure and boundary condition. For the developed model, the electric field is zero after $\mathrm{r}=0 \mathrm{~m}$ because of the conductor region. The next region after the conductor consists of the insulation material. The magnitude of EF is at peak at the nearest area to the conductor and drops within the insulation material at the site 
far away from the conductor. After the first and second insulation layer as shown in Figure 5, the magnitude of electric field is nearly identical within the bushing region made of the porcelain insulation material. There is discontinuous electric field between the insulation material porcelain and the air layer next to it, because the air permittivity is different.

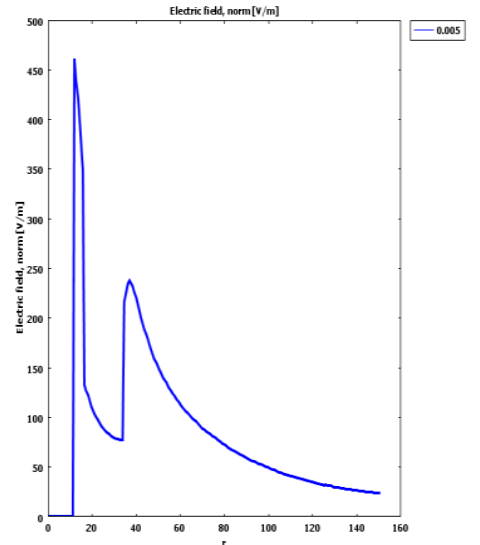

Fig. 5. Cross-sectional view of electric field in the bushing model

Figure 6 shows the magnitude of EF at a definite point in the insulation material subjected to the material permittivity for the developed model. It has been found in the developed model that the magnitude of electric field decreases when material permittivity is higher.

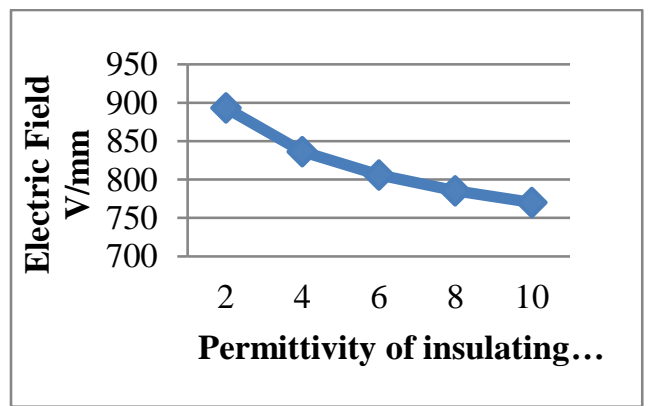

Fig. 6. Relation between the electric field and permittivity of the insulating material.
The permittivity defines the capability of the insulation material to align the EF. Therefore, a higher permittivity of the insulation means that the aptitude of the insulation to align the $\mathrm{EF}$ is better, resulting in less EF attentiveness in the insulation material. For Figures 6, the magnitude of EF in the bushing subjected to the permittivity of the insulation material.

\section{Conclusion}

The two dimensional axial symmetry model of transformer bushing was made through the Finite Element Analysis (FEA) technique. The simulation was done to examine the distribution of EF in transformer bushing. The effect of the bushing permittivity has also been studied. From the simulation results, it was found that the high $\mathrm{EF}$ is mainly concentrated at the edge of aluminum cap and bushing plate. It was also concluded that the magnitude of EF in the bushing is inversely proportional to the permittivity HV bushing material.

\section{REFERENCES}

[1]. Sumereder, C. and Muhr. M. "Dielectric response measurements at high voltage bushings". International Conference on Condition Monitoring and Diagnosis pp.1150-1153. 2008

[2]. Setayeshmehr,A.,"On-line monitoring and diagnoses of power transformer bushings," IEEE Transactions on Dielectrics and Electrical Insulation, Vol. 13, pp. 608-615. 2006

[3]. Lokhanin,A.K, G.Y. Shneider, V.V. Sokolov, and V.M. Chornogotsky, "Internal Insulation Failure Mechanisms of HV Equipment Under Service Conditions," Cigre, pp. 1- 6.2002.

[4]. Lord,T., and Hodge,G, "On-line Monitoring Technology Applied to HV Bushings,". AVO Technical Paper pp. 03-08.2005. 
[5]. Pukel,G.J., H. M. Muhr and W. Lick. "Transformer diagnostics: Common used and new methods," International conference on Monitoring and Diagnosis, CMD Changwon, Korea. vol. 36607, p. 15463.2006.

[6]. J. S. Graham, "High Voltage Bushings," in High Voltage Engineering and Testing, H. M. Ryan, Ed. London, United Kingdom: The Institution of Electrical Engineers, 2001, ch. 12, pp. 405-434.

[7]. http://www.hivoltinsulators.com/uploa $\mathrm{d} / 20171129 / \mathrm{a} 4004 \mathrm{~b} 4 \mathrm{c} 9 \mathrm{e} 207 \mathrm{~d} 55 \mathrm{c} 9355 \mathrm{c}$ 6e3d0471ea.jpg.

[8]. T. Seghir, D. Mahi, T. Lebey, and D. Malec, "Analysis of the Electric Field and the Potential Distributions in Cavities Inside Insulation Electric Materials,"COMSOL Users Conference, Paris, France, 2006.

[9]. A.E. Davies and G. Chen, "Electric Stress Distribution in Polymeric Insulation Containing Defectd Sites and Space Charges," The International Journal for Computation and Mathematics in Electrical and Electronic Engineering, vol. 11, no. 1, pp. 237-240, 1992.

[10].Lijun Jin; Yifei Xue; Bonan Zhao; Jie Chen; Wenhao Zhang "Electric field calculation and insulation analysis of high voltage insulating bushing". Electric Power Equipment - Switching Technology (ICEPE-ST), International Conference, 2013.

[11]. Amit Kumar Mehta; R. N. Sharma; Sushil Chauhan; S. D. Agnihotri "Study and diagnosis of the power transformer bushing insulation system". IEEE Pulsed Power Conference, 2011. 